Kozyra Magdalena, Klas Jakub, Szabat Marta, Samoń-Drzewicka Anna, Milanowska Joanna. The relationship between the diet, microelements, macronutrients and vitamins on the schizophrenia - literature analysis. Journal of Education, Health and Sport. 2020;10(9):369-377. eISSN 23918306. DOI http://dx.doi.org/10.12775/JEHS.2020.10.09.043

https://apcz.umk.pl/czasopisma/index.php/JEHS/article/view/JEHS.2020.10.09.043

https://zenodo.org/record/4035325

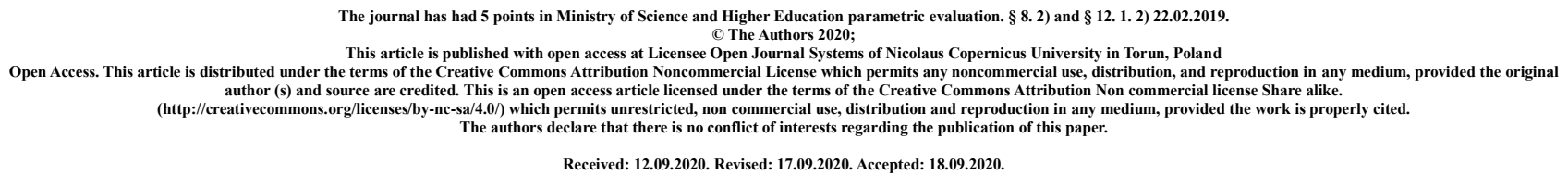

\title{
The relationship between the diet, microelements, macronutrients and vitamins on the schizophrenia - literature analysis
}

\author{
Magdalena Kozyra ${ }^{1}$, Jakub Klas ${ }^{1}$, Marta Szabat ${ }^{1}$, Anna Samoń-Drzewicka ${ }^{2}$, \\ Joanna Milanowska ${ }^{3}$
}

(1) Student Research Group of Applied Psychology, Medical University of Lublin

(2) Student Scientific Group of Traditional and Innovative Internal Medicine, Poznan University of

Medical Sciences

(3) Department of Applied Psychology, Medical University of Lublin

*Address for correspodence: Staffa 24, 20-454 Lublin, telephone number: 695562174 , e-mail address: madzia.kozyra.1221@poczta.onet.pl

\section{ORCID ID and E-mail}

Magdalena Kozyra https://orcid.org/0000-0002-0260-4102 madzia.kozyra.1221@poczta.onet.pl

Jakub Klas https://orcid.org/0000-0002-4795-1909 jakubklas99@gmail.com

Marta Szabat https://orcid.org/0000-0001-6309-2027 marta.szabat9@gmail.com

Anna Samoń-Drzewicka https://orcid.org/0000-0002-2077-2783 anna.samon.drzewicka@gmail.com Joanna Milanowska https://orcid.org/0000-0001-9741-1583 joannamilanowska@umlub.pl 


\section{ABSTRACT}

Introduction: Schizophrenia is a disease that affects approximately $1 \%$ of the population. It begins in adult humans. It turns out that there are factors that predispose to schizophrenia, and by modifying your lifestyle, you can reduce the likelihood of its occurrence. One of such factors is the diet and microelements, macronutrients and vitamins that we consume every day.

The aim of the study: The aim of this study was to find out the relationship between the diet, microelements, macronutrients, vitamins and the schizophrenia disease.

Material and method: The research of articles was done in the websites such as PubMed and Google Scholar.

Description of the state of knowledge: Ketogenic and gluten-free diet are promising tools in decreasing the symptoms of and treating schizophrenia. Micro- and macroelement imbalances are present in schizophrenic patients, but their correlation with development of schizophrenia is not clear. Folate, vitamin D and vitamin B12 supplementation could prove useful in the treatment.

Summary: There are many studies that try to combine the implications of a balanced diet and the proper supply of elements and their impact on schizophrenia's occurrence and symptomology. Still, further investigation of these topics is needed to provide the most suitable guidelines and applications of proper nutrition of schizophrenic patients.

Key words: schizophrenia; diet; microelements; macronutrients; vitamins;

\section{INTRODUCTION}

Schizophrenia is a mental disorder classified as psychosis. Statistics show that it occurs in about $1 \%$ of the population. The peak incidence of schizophrenia occurs around 18-35 years of age [1]. Because often the first symptoms - the first episode of psychosis - occur suddenly, and in adulthood it is difficult for new patients to come to terms with the new reality. For this reason, comorbidities such as depression, anxiety disorders or neurosis often appear among these patients. In addition, patients often fall into a vicious circle - they use psychoactive substances to relieve the disease, thus making it worse.

There are many factors cited by many scientists around the world as having the potential to influence over the development of schizophrenia. They distinguish factors such as: environmental, neurological, sociological and, of course, genetic factors. And in addition to the influence of certain factors on DNA methylation and the subsequent development of schizophrenia, heredity is also cited as the cause of schizophrenia. Statistics show up to $18 \%$ chance of developing schizophrenia if this disease occurs in one of the parents, and in the case when both parents suffer from illness, the risk increases even to over $20 \%$ [2].

In patients with schizophrenia, social problems can often be observed. Such people are often withdrawn, have few friends, have problems with finding a job, which is also often associated with poverty and homelessness. They also often have a lower level of completed education [3], worse living conditions and worse results in relation to healthy people, on the scales examining the quality of life in humans [4]. 
Interestingly, we can say about another vicious circle on the example of several problems that may result from schizophrenia. Just as schizophrenia may make it difficult for a patient to start work and lead to unemployment and poverty, in itself, for example, poverty is also often reported as a risk factor for the development of schizophrenia [5]. In addition, the factors predisposing include discrimination, dysfunctions and pathologies in the family, and childhood trauma [6].

There are several types of schizophrenia. Each type has slightly different symptoms of the disease, a different neurological cause, and therefore different groups of drugs are used for them. Neurologically, in schizophrenia, there is hyperactivity of dopaminergic neurotransmission - the dopaminergic D2 receptor. Therefore, if there are positive symptoms (such in which the patient complains of hallucinations or delusions), which are the result of dopaminergic hyperactivity, classic neuroleptics are used in pharmacological treatment - receptor D2 antagonists. These drugs are designed to calm the patient. Unfortunately, their most serious side effect may be drug-induced neuroleptic malignant syndrome.

In the case of negative symptoms, when there are symptoms of gradual withdrawal and "silence" of the patient (most often in the late stages of the disease), atypical drugs are used, the greatest side effect of which is the metabolic syndrome and increase in the patient's weight. In addition, people with schizophrenia have a higher risk of developing type 2 diabetes mellitus (T2DM)[7], which, together with the metabolic syndrome with atypical drugs, may additionally have a very negative impact on the health of people suffering from schizophrenia. Atypical drugs inhibit receptors such as 5HT2, $\alpha 1, \mathrm{H} 1$ and M1 to the greatest extent.

And now, knowing how the transmission of neurotransmitters changes during the disease, drugs can be used to affect neurotransmission, e.g. dopaminergic, but other substances that are not drugs but can affect the nervous system can also be used. For example, knowing that NMDA defects are observed in schizophrenia, which may eventually even result in prefrontal cortex defects, other causes of NMDA defects were searched for. It turned out that the glutathione precursor N-acetyl cysteine (NAC) can prevent these changes and further reduce the risk of schizophrenia [8]. It is related to its antioxidant activity, which confirms the belief that one can try to prevent or even support basic pharmacotherapy with other scientifically proven methods.

\section{MATERIALS, METHODS AND AIM}

The aim of this work was to find out the relationship of the diet on the schizophrenia and the relationship between the intake of micro-/macroelements and vitamins also on the schizofrenia disease. The research of articles which cover these topic was done by usage of the scientific search engines such as PubMed and Google Scholar. 


\section{DEPENDENCE OF DIET ON THE SCHIZOPHRENIA}

People with schizophrenia are more prone to civilization diseases than the general population [9]. A study on mortality in schizophrenia showed that people with schizophrenia have an increased relative risk of premature death, dying at least 10 years earlier than their peers of the same age [10]. In addition, it has been investigated that two-thirds of the excess deaths are attributed to cardiovascular disease, respiratory disease and T2DM [10], which can be prevented by changing patients' lifestyle.

The justification for the occurrence of cardiovascular disease and T2DM can be attributed to poor eating habits. A case-control study in the Scottish population showed that people with schizophrenia make poor food choices [11]. Patients consumed much less energetic meals, clearly reduced amounts of fiber, retinol, carotene, vitamin $\mathrm{C}$ and vitamin $\mathrm{E}$ compared to the control group, but obtained more energy from saturated fat than suggested [11]. In a 2003 McCreadie et al. after examining dietary consumption in a sample of 102 people with schizophrenia, shown that these patients consumed an average of 16 servings of vegetables and fruit per week, which is less than half of the recommended weekly intake [12]. Antipsychotic drugs also have a significant negative effect on body weight. Clozapine and olanzapine show the greatest tendency to cause weight gain, their effect may increase weight by $4.5 \mathrm{~kg}$ after 10 weeks of treatment with the standard dose [13]. One study found that the use of clozapine to treat schizophrenia over a 10-year period would result in 416 deaths per 100,000 patients caused by clozapine, reducing the effectiveness of treatment to prevent patients from committing suicide [14].

It seems that one of the solutions for improving the treatment of disease and patients' health would be a ketogenic diet. This diet, apart from the possibility of losing weight, could be successfully used in the treatment of the disease. Polish authors of the article [15] hypothesize that the ketogenic diet changes the GABA: glutamate ratio in favor of GABA. As a result, catabolism is inhibited and GABA synthesis is stimulated, as well as increases glutamate metabolism, which could help balance the disturbed GABA levels in the schizophrenic brain. This could lead to a possible better disease outcome in reducing symptoms and preventing weight gain with some medications used. The effectiveness of the use of the ketogenic diet on young people at this time was demonstrated, for example, in the case report from Ecuador [16], where in two patients treated for schizophrenia (twins, a woman and a man) after dieting, a reduction in both the PANSS and BMI values in both patients and normalization of liver enzymes in a man. In addition, postmortem studies of the prefrontal cortex and the results of in vivo NMR spectroscopy have shown that there is a bioenergetic dysfunction characterized by abnormal glucose processing and mitochondrial dysfunction, which results in impaired synaptic communication in the brain of people with schizophrenia [17]. In contrast, the ketogenic diet, which provides an alternative fuel for glucose for bioenergy processes in the brain, normalizes schizophrenia-like behavior among the studied mouse models [17].

There are also scientific studies confirming the beneficial effect of a gluten-free diet on the quality of life of patients with schizophrenia [18]. In 1976, an article in Science showed the effect of wheat gluten on the development of schizophrenia [19]. Data from all forms of observation of patients treated with wheat gluten indicated that wheat gluten increased the symptomology of schizophrenia and decreased response to treatment. During the gluten challenge, treatment progress stopped or even reversed, only to resume after gluten removal [19]. 
In turn, the results of Reichelt's studies confirm the view that gluten-free diet is beneficial for some patients and indicate that abnormally high levels of peptides in urine found in some patients with schizophrenia may be reversibly changed by the use of the above-mentioned diet. Researchers noticed significant changes in those patients who followed a gluten-free diet for at least 2 years [L20]. On the other hand, Jackson's study showed an improvement in the treatment of schizophrenia after dieting in a patient who was diagnosed with anti-tissue transglutaminase (tTG) antibodies and in a patient with known anti-gliadin antibodies (AGA). Both participants improved their overall BPRS score and the Negative Symptom Rating Scale, reported good diet tolerance, maintained a stable weight, and improved serum antibody scores [21].

It should be noted that any attempt to modify the current eating habits will probably have to be associated with mandatory monitoring of compliance by the supervising physician. A randomized controlled trial showed that patients with schizophrenia eagerly consumed the free fruit and vegetables during the study period, but 12 months after the end of the campaign, consumption returned to the same level as before the start of the study. Therefore, the control of eating habits in patients with schizophrenia must be carried out all the time [22].

It is important to remember to educate the patient that nutritional changes may be an additional therapy. They can help their fight with a disease, but they can never replace proper treatment which include pharmacotherapy.

\section{DEPENDENCE OF MICROELEMENTS, MACRONUTRIENTS AND VITAMINS ON THE SCHIZOPHRENIA}

Many substances impact on the proper functioning of the body. Among them there are macro and trace elements and vitamins. Both, deficiency and excess of them can impact on the function of human body and manifestation of some diseases. The attempt was made to define if concentration of chemical elements in blood serum correlate with appearance of schizophrenia. Study by Lin et al. included concentration both, macro and trace element in blood serum. It showed, that in more than half of the substances, the result was statistically significantly different between the research group and the healthy controls. The difference in concentration of chemical elements in blood serum of patients with schizophrenia concerned especially elements like: titanium (To), boron (B), sulfur (S), calcium (Ca) and sodium $(\mathrm{Na})$. To a lesser extent, it concerned Magnesium and elements: Al, As, B, Bi, Ca, Cd, Co, $\mathrm{Cu}, \mathrm{Fe}, \mathrm{Gd}, \mathrm{Li}, \mathrm{Mn}, \mathrm{Na}, \mathrm{Ni}, \mathrm{P}, \mathrm{Rb}, \mathrm{S}, \mathrm{Se}, \mathrm{Sn}, \mathrm{Sr}, \mathrm{Th}, \mathrm{Ti}, \mathrm{Tl}, \mathrm{V}$ [23].

Also study by Ma et al. described statistically significant difference in content of selected macro and trace elements in blood serum of research group and healthy control. Study included 11 chemical elements - Ca, K, Mg, Na, Se, Zn, Mn, Co, Mo, Cu and Fe. Concentration of six of them - calcium, potassium, magnesium, selenium and zinc was significantly lower in blood serum of schizophrenic patients in comparison to healthy control. In this case study described significantly increased concentration of manganese and cobalt in blood serum of patients in comparison to healthy control. While concentration of molybdenum, copper and iron were on similar level in both, patients as well as a healthy control. Study showed also correlation between risk of schizophrenia appearance and decreased levels of $\mathrm{Ca}, \mathrm{Na}, \mathrm{Mg}$, Se and increased concentration of $\mathrm{Mn}$ [24]. 
Increased concentration of manganese as a potential risk factor of schizophrenia was described also by Liu et al. This study points increased level of chromium and low concentrations of selenium, iron, arsenic, copper, aluminum and nickel as substances connected with risk of appearance of schizophrenia either. There was also no correlation between concentration of molybdenum and zinc in blood serum and risk of schizophrenia [25]. While meta-analysis carried out by Joe et al. points out that there is a connection between concentration of zinc in blood serum and appearance of schizophrenia. It indicated occurrence of lower levels zinc in patients' blood serum than in healthy control [26].

For different connection between risk of schizophrenia appearance and concentration of macro and trace elements in blood serum points out Cao et al. In this study author describes occurrence of lower levels of manganese in blood serum of patients with schizophrenia who experienced the first episode as well as in the group of people with recurrent episodes of schizophrenia compared to the healthy control. Furthermore in the group of patients with recurrent episodes of schizophrenia study found lower level of molybdenum either. Furthermore, in group of schizophrenic patients study point out decreased concentration of iron and nickel. While in the rest of chemical elements included in this study - zinc, copper, cobalt, there wasn't statistically significant differences. Author points out that there is correlation between lower concentration of manganese and molybdenum and appearance of schizophrenia as well as an increased concentration of iron and nickel in blood serum and appearance of schizophrenia [27].

Connection between decreased concentration of manganese in group of patients with schizophrenia is showed in study by $\mathrm{Li}$ et al. either. It points out on decreased levels of $\mathrm{Se}, \mathrm{Cd}, \mathrm{Pb}, \mathrm{Ca}$, $\mathrm{Cu}$ and $\mathrm{Fe}$ in research group compared to healthy control. The concentration of boron, chromium, arsenic, potassium and magnesium in blood serum in patients was on higher level than in healthy control while between concentration of zinc in research group and healthy control there was no statistically significant differences [28].

The existence between vitamins level and an increased risk of appearance of schizophrenia has also been studied. In their study Goff et al. points out on significantly reduced level of folate in blood serum of patients with schizophrenia, which correlates with the occurrence of negative symptoms [29]. Similarly as Goff, also Herran et al. point out that there are statistically significant decreased levels of folate in schizophrenic patients blood serum. Lower levels of folate was noticed in blood serum of patients, who suffer from hebephrenic schizophrenia, but this study didn't showed statistically significant difference between different types of schizophrenia [30].

Also, there was noticed impact of other vitamins to risk of appearance of schizophrenia. Study by McGrath et al. describe connection between vitamin D (25(OH)D3) deficiency and risk of appearance of schizophrenia. In their study their conclude that deficiency of $25(\mathrm{OH}) \mathrm{D} 3$ in mother's blood serum can be a risk factor to abnormal brain development in prenatal life and increased level of risk of schizophrenia later in life [31]. On lower level of vitamin D at adults schizophrenic patients blood serum point out study by Itzhaky et al. either. However, it doesn't find connection between the severity of the symptoms of the disease and concentration of vitamin D in blood serum [32].

Vitamin B12 also can relate with risk of schizophrenia appearance. Study by Zhang et al. showed reduced level of vitamin B12, especially it form - MeCbl at patient with schizophrenia [33]. Kemperman et al. also indicate the decreased concentration of vitamin B12 in the organism of schizophrenic patients [34]. 


\section{SUMMARY}

In order to summarise the influence of diet on symptomology of schizophrenic patients, it is worth noting first that due to their state, such patients tend to neglect healthy nutrition habits, what together with adverse effects of drugs such as neuroleptics (clozapine, olanzapine) might lead to dietinduced health issues such as obesity or T2DM [9]. Studies researching possible positive effects of proper diet on schizophrenia-related symptoms showed promising results regarding the ketogenic and gluten-free diet.

Ketogenic diet, used primarily for weight loss and T2DM on its own is useful in controlling the adverse effects of the neuroleptic-based treatment. Also, it helps to improve brain's pathologically changed metabolism [15,17].

In matters of gluten-free diet, it might be useful in decreasing schizophrenic symptoms. High gluten intake correlates with increased symptoms and decreased effectiveness of the treatment [19]. Thus reducing this intake might prove useful. So far evidence shows that administration of such diet needs to last at least 2 years in order to give visible effects [20].

When it comes to micro- and macroelement level dysregulation in schizophrenia, many studies were conducted and their results seem to be discussible between one another. It was shown that indeed many elements such as manganese, sodium or zinc seem to be lower in schizophrenic patients while selenium correlates with higher risk of this disorder's occurrence [23,24,26].

It was shown that in schizophrenic patients lower level of folates positively correlates with increased negative symptoms [29]. Deficit of vitamin D during pregnancy increases the risk of schizophrenia development in the offspring [31]. Also adult schizophrenic patients tend to have lower vitamin D levels, although evidence for correlation between vitamin D deficiency and increased symptoms is lacking [32]. Vitamin $\mathrm{B}_{12}$ also seems to be low in schizophrenic patients [33,34].

To summarise, application of proper diet and supplementation might prove useful in treatment of schizophrenic patients and could help controlling their symptoms. It would however require regular dietary controls and constant monitoring of the patients who tend to easily return to neglecting proper nutrition habits. Such solution involves financial implications for the patients and might be hard to implement on a larger scale. However, as up-to-date results seem to be promising, further research is needed for precise guidelines to arise. 


\section{REFERENCES}

[1] Whiteford HA, Degenhardt L, Rehm J, Baxter AJ, Ferrari AJ, Erskine HE, Charlson FJ, Norman RE, Flaxman AD, Johns N, et al. Global burden of disease attributable to mental and substance use disorders: findings from the Global Burden of Disease Study 2010. Lancet. 2013;382:1575-1586. doi: 10.1016/S0140-6736(13)61611-6.

[2] [1] Janoutová J, Janácková P, Serý O, Zeman T, Ambroz P, Kovalová M, Varechová K, Hosák L, Jirík V, Janout V. Epidemiology and risk factors of schizophrenia. Neuro Endocrinol Lett. 2016;37(1):1-8.

[3] Palijan TŽ, Kovačević D, Vlastelica M, Dadić-Hero E, Sarilar M. Quality of Life of Persons Suffering from Schizophrenia, Psoriasis and Physical Disabilities. Psychiatr Danub. 2017 Mar;29(1):60-65

[4] Hofer A, Mizuno Y, Wartelsteiner F, Wolfgang Fleischhacker W, Frajo-Apor B, Kemmler G, Mimura M, Pardeller S, Sondermann C, Suzuki T, Welte A, Uchida H. Quality of life in schizophrenia and bipolar disorder: The impact of symptomatic remission and resilience. Eur Psychiatry. 2017 Oct;46:42-47

[5] Mueser K.T., McGurk S.R., Schizophrenia. The Lancet, 363 (9426), London, England 2004, s. 2063-2072, DOI: 10.1016/S0140-6736(04)16458-1, PMID: 15207959.

[6] Janssen I. et al. Childhood abuse as a risk factor for psychotic experiences, „Acta Psychiatrica Scandinavica”, 109 (1), 2004, s. 38-45, PMID: 14674957.

[7] Suvisaari J, Keinänen J, Eskelinen S, Mantere O. Diabetes and Schizophrenia. Curr Diab Rep. 2016 Feb;16(2):16

[8] Phensy A, Driskill C, Lindquist K, Guo L, Jeevakumar V, Fowler B, et al. Antioxidant Treatment in Male Mice Prevents Mitochondrial and Synaptic Changes in an NMDA Receptor Dysfunction Model of Schizophrenia. eneuro. 2017;4. doi:10.1523/eneuro.0081-17.2017.

[9] Mccreadie, R. G., Kelly, C., Connolly, M., Williams, S., Baxter, G., Lean, M., \& Paterson, J. R. (2005). Dietary improvement in people with schizophrenia. British Journal of Psychiatry, 187(4), 346-351. doi:10.1192/bjp.187.4.346

[10] Joukamaa, M., Heliovaara, M., Knekt, P. et al (2001) Mental disorders and cause specific mortality. British Journal of Psychiatry, 179, 498-502

[11] McCreadie, R. G., MacDonald, E., Blacklock, C. et al (1998) Dietary intake of schizophrenia patients in Nithsdale, Scotland: Case Control Study. BMJ; 317, 784-785

[12] McCreadie, R. G. (2003) Diet, smoking and cardiovascular risk in people with schizophrenia. Descriptive study. British Journal of Psychiatry, 183, 534-539

[13] Zimmerman, U., Kraus, T., Himmerich, H. et al (2003) Epidemiology, implications and mechanisms underlying druginduced weight gain in psychiatric patients. Journal of Psychiatric Research, 37, 193-220

[14] Fontaine, K. R., Moonseong, H., Harrigan, E. P. et al (2001) Estimating the consequences of antipsychotic induced weight gain on health and mortality rate. Psychiatric Research, 101, 277-288

[15] Włodarczyk, A., Wiglusz, M. S., \&amp; Cubała, W. J. (2018). Ketogenic diet for schizophrenia: Nutritional approach to antipsychotic treatment [Abstract]. Medical Hypotheses, 118, 74-77. doi:10.1016/j.mehy.2018.06.022

[16] Gilbert-Jaramillo, J., Vargas-Pico, D., Espinosa-Mendoza, T., Falk, S., Llanos-Fernandez, K., Guerrero-Haro, J., . . . Palmer, C. (2018). The effects of the ketogenic diet on psychiatric symptomatology, weight and metabolic dysfunction in schizophrenia patients. Clinical Nutrition and Metabolism, 1(1). doi:10.15761/cnm.1000105

[17] Ketogenic diet for schizophrenia: Clinical implication. (n.d.). Retrieved September 13, 2020, from https://www.ncbi.nlm.nih.gov/pubmed/31192814

[18] Levinta, A., Mukovozov, I., \& Tsoutsoulas, C. (2018). Use of a Gluten-Free Diet in Schizophrenia: A Systematic Review. Advances in Nutrition, 9(6), 824-832. doi:10.1093/advances/nmy056

[19] Singh M, Kay SR. Wheat gluten as a pathogenic factor in schizophrenia. Science 1976;191(4225):401-2

[20] Reichelt KL, Sagedal E, Landmark J, Sangvik BT, Eggen O, Scott H. The effect of gluten-free diet on urinary peptide excretion and clinical state in schizophrenia. J Orthomol Med 1990;5(4):223-39.

[21] Jackson J, Eaton W, Cascella N, Fasano A, Warfel D, Feldman S, Richardson C, Vyas G, Linthicum J, Santora D et al. A gluten-free diet in people with schizophrenia and anti-tissue transglutaminase or anti-gliadin antibodies. Schizophr Res 2012;140(1-3):262-3

[22] McCreadie, R., Kelly, C., Connolly, M., Williams, S., Baxter, G., Lean, M., \& Paterson, J. (2018, January 02). Dietary improvement in people with schizophrenia: The British Journal of Psychiatry. Retrieved September 13, 2020, from https://doi.org/10.1192/bjp.187.4.346 
[23] Lin T, Liu T, Lin Y, Yan L, Chen Z, Wang J. Comparative study on serum levels of macro and trace elements in schizophrenia based on supervised learning methods. J Trace Elem Med Biol. 2017;43:202-208. doi:10.1016/j.jtemb.2017.03.010

[24] Ma J, Yan L, Guo T, et al. Association between Serum Essential Metal Elements and the Risk of Schizophrenia in China. Sci Rep. 2020;10(1):10875. Published 2020 Jul 3. doi:10.1038/s41598-020-66496-7

[25] Liu T, Lu QB, Yan L, et al. Comparative Study on Serum Levels of 10 Trace Elements in Schizophrenia. PLoS One. 2015;10(7):e0133622. Published 2015 Jul 17. doi:10.1371/journal.pone.0133622

[26]Joe P, Petrilli M, Malaspina D, Weissman J. Zinc in schizophrenia: A meta-analysis. Gen Hosp Psychiatry. 2018;53:1924. doi:10.1016/j.genhosppsych.2018.04.004

[27] Cao B, Yan L, Ma J, et al. Comparison of serum essential trace metals between patients with schizophrenia and healthy controls. J Trace Elem Med Biol. 2019;51:79-85. doi:10.1016/j.jtemb.2018.10.009

[28] Li Z, Liu Y, Li X, et al. Association of Elements with Schizophrenia and Intervention of Selenium Supplements. Biol Trace Elem Res. 2018;183(1):16-21. doi:10.1007/s12011-017-1105-0

[29] Goff DC, Bottiglieri T, Arning E, et al. Folate, homocysteine, and negative symptoms in schizophrenia. Am J Psychiatry. 2004;161(9):1705-1708. doi:10.1176/appi.ajp.161.9.1705

[30] Herrán A, García-Unzueta MT, Amado JA, López-Cordovilla JJ, Díez-Manrique JF, Vázquez-Barquero JL. Folate levels in psychiatric outpatients. Psychiatry Clin Neurosci. 1999;53(4):531-533. doi:10.1046/j.1440-1819.1999.00572.x

[31] McGrath JJ, Eyles DW, Pedersen CB, et al. Neonatal Vitamin D Status and Risk of Schizophrenia: A Population-Based Case-Control Study. Arch Gen Psychiatry. 2010;67(9):889-894. doi:10.1001/archgenpsychiatry.2010.110

[32] Itzhaky D, Amital D, Gorden K, Bogomolni A, Arnson Y, Amital H. Low serum vitamin D concentrations in patients with schizophrenia. Isr Med Assoc J. 2012;14(2):88-92.

[33] Zhang Y, Hodgson NW, Trivedi MS, et al. Decreased Brain Levels of Vitamin B12 in Aging, Autism and Schizophrenia. PLoS One. 2016;11(1):e0146797. Published 2016 Jan 22. doi:10.1371/journal.pone.0146797

[34] Kemperman RF, Veurink M, van der Wal T, et al. Low essential fatty acid and B-vitamin status in a subgroup of patients with schizophrenia and its response to dietary supplementation. Prostaglandins Leukot Essent Fatty Acids. 2006;74(2):75-85. doi:10.1016/j.plefa.2005.11.004 